\title{
FARMART: COMPLETE SOLUTION OF SMART FARMING
}

\author{
Lucky Yadav $^{1}$, Mr.Karthick.S ${ }^{2}$ \\ ${ }^{1}$ Student of B.Tech (CSE) SRM Institute of Science and Technology NCR Campus, \\ ${ }^{2}$ Assistant Professor of BTech CSE Department in SRM Institute of Technology NCR Campus
}

Article DOI: https://doi.org/10.36713/epra7105

DOI No: 10.36713/epra7105

\begin{abstract}
With the increase in technology related to IoT, the concepts are being readily applied to Smart Agriculture that can help in providing data about the land as per the provided input. The farmart is a complete solution of smart farming. Which is developed for the farmers to optimize use of water for agricultural crop. As water supply is becoming a scare in today's life it is important to adopt the smart solution in farming also. The project describes how irrigation can be handle smartly using IOT. This project can help farmers to save their time and give complete information about the soil and climate by which farmers can decide when crop needs water and as it's a smart farming it can be done automatically by the farmart. The primary aim of the project is used for detecting soil moisture and climate condition and depending on the condition it sprinkle the water in field. And this entire information is sent to user's mobile phone through SMS. This system involves using a WSN with different sensor which help farmart to take action. And this whole system is programmed into a microcontroller which control the irrigation system and quantity of water being used. And then send this information to user with the help of duplex communication channel working on an interface of cellular-internet which allow user to get every information on his phone through an app and a webpage.
\end{abstract}

\section{INTRODUCTION}

Smart farming is a model which consist of modern and smart technology for increasing the quality and quantity of the product. Farming is backbone of our country economy and 70 percent of people in our country depends on farming. Most of farming and agriculture methods work on mere predicting the weather, which in case the prediction fails, the farmers are left with huge loss.

The main objective of designing a smart farming method is to make a decision-making system for farmers and help them in agriculture so that productivity increases. Smart farming saves the time and money of farmers and help them to get huge profit with less effort. IoT based smart farming helps farmers to achieve data about the field by using sensors as farmers in $21^{\text {st }}$ century has access to modern equipment's and technologies like GPS, Soil Sensors, IOT based product.

The research aimed on designing a smart Farming system applying the technology of Internet of Things, with Agriculture system, to monitor the soil moisture, temperature and the Humidity level on a very low cost, to make live monitoring easy and by analysing the data from system the water pump switches-on and off automatically and the whole process information and data send to farmers mobile phone through SMS, E-mail, a dedicate app and a webpage.

\section{LITERATURE SURVEY}

Joaquín Gutiérrez et al. (2014), The research involves optimizing the usage of water for crops. The authors developed an algorithm with threshold soil moisture and temperature values, programmed into a gateway using micro-controllers for controlling the quantity of water usage.

Shakthipriya N. et al. (2014), reviewed a number of state-of-art farming methods detailed in numerous studies which involves the wireless sensor technology. The research was centred on values of soil moisture, to turn on the sprinklers during the time of water scarcity. 
G. Meena Kumari et al. (2014), details an approach proposing to monitor and control the parameters of greenhouse in agriculture precision using Wireless Sensor Network, and the related technology.

S. Sivachandran, et al. (2014), the authors under the research proposed a soil analysing device which measured the soil $\mathrm{pH}$ values, and helps in detailing the soil nutrients levels. Their systems used a thermal printer, a power supply, sensors, microcontroller unit, display, and signal conditioning. The device designed by them helps in predicting the soil sequence as per the nutrient values.

Chandan Kumar Sahu, et al. (2015), the authors proposed a model to control and supervise the direction and flow of water. Their approach had a soil moisture and a DHTT11 sensor. Their device proposed a way of selecting the water direction and the related data can also be sent to the Gmail account or on the phone of the farmer.

Ritika Srivastava, et al. (2020), in their study offered an efficient support system for decision making using WSN that can help in handling different farm activities, which provides useful fata related to their land like the Humidity content, Soil moisture, and Temperature.

Anand Nayyar, Vikram Puri et al (2016), aimed their research on proposing a Smart Stick based in IoT technology which can help the farmers to get live monitoring data of the environment temperature and content soil moisture, on very low cost.

\section{METHODOLOGY}

\subsection{Internet of Things}

IoT is described as a network of physical objects that are embedded system and sensors for exchanging data between them and other devices over internet. IoT helps in making many technologies around the world smart and responsive, merging the physical and digital frameworks

\subsection{Cascading Style Sheet (CSS)}

CSS is a language which can be used in describing a document presentation coded in HTML.

\subsection{Java Script (JS)}

Another programming language which confirms with the specification of ECMS Script. It helps in enabling the interactive web pages and is an important part of web application

\subsection{PHP}

A Server-script language program which is a powerful tool to design interactive and dynamic web pages.

\subsection{Structured Query Language (SQL)}

This was designed to manage data in the relational system of data base management.

\section{IMPLEMENTATION}

In the following part of the paper, a smart agriculture system is designed using IoT Technology to monitor live values of Moisture, temperature and humidity using Arduino, Sensors and other equipment.

\subsection{Working of Farmart}

Smart Farming Based Agriculture IoT System- FARMART is regarded an Internet of Things enabled device aiming on monitoring the live data about the environmental parameters like the Moisture, humidity, Temperature, and other values according to the type of sensors used in the system. Agricultural IOT smart system can also send information to other devices as well like Tablets, Smart phones, etc. However, the app and a webpage and the data generated by the sensors analysed and if soil is dry and temperature is high automatically the water pump switch on after some time the reading is taken again and if the soil is wet the water pump automatically off and a message and a mail is send to the farmer using GSM modem and this data via sensors could be viewed and shared anywhere easily with the consultants of agriculture siting remotely through the android app and webpage.

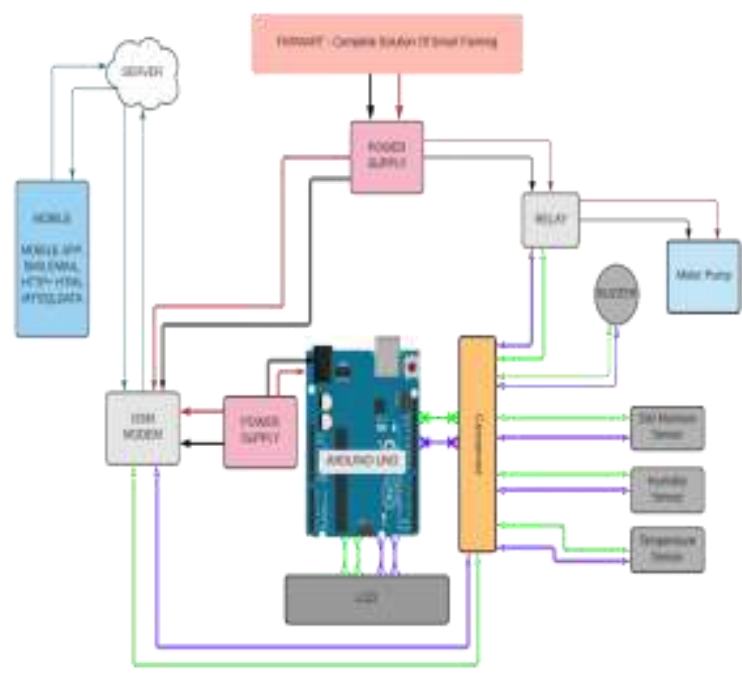

Figure 1: Proposed Diagram Of FARMART

\subsection{Components}

Different components like the sensors and modules used in the FARMART system are discussed. 


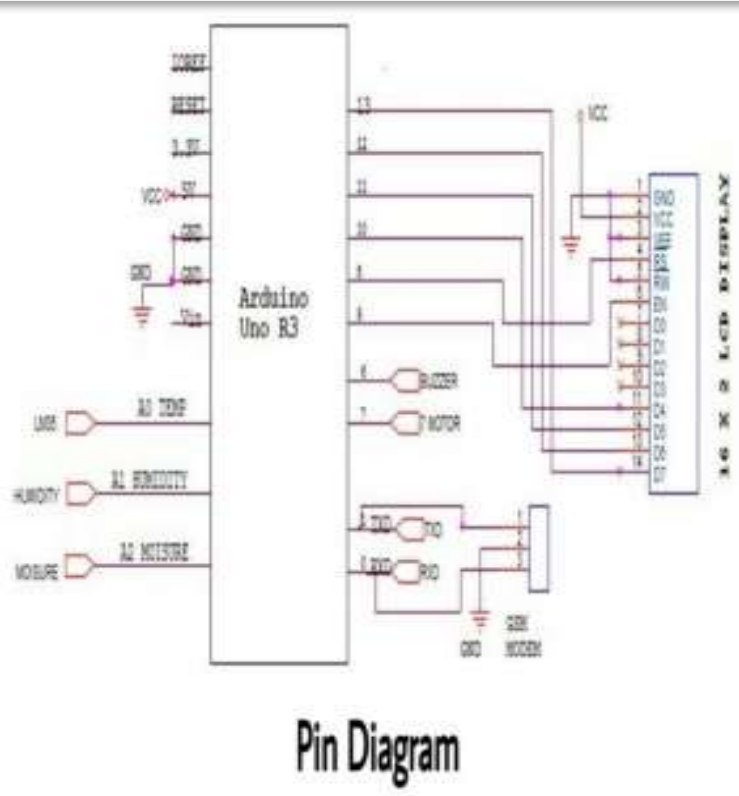

Figure 2: Circuit Diagram of System

\subsubsection{Arduino}

A Micro-controller chip called the Arduino Uno is based on ATmega328. It is comprised of analog inputs, 14 Digital output and input pins (with 6 PWM outputs pins), a USB pin, $16 \mathrm{MHz}$ crystal oscillator, a reset button, a power jack, an ICSP header. An Arduino chip is comprised of every requirement needed to support a micro-controller, to connect in to the computer in a simple manner with a power jack, a USB pin with a battery, an AC-to-DC converter. This Arduino Uno chip is different from other boards as it does not use another USB-to-serial FTDI driver chip. As the Uno chip features a programming Atmega8U2, USB-to-serial converter.

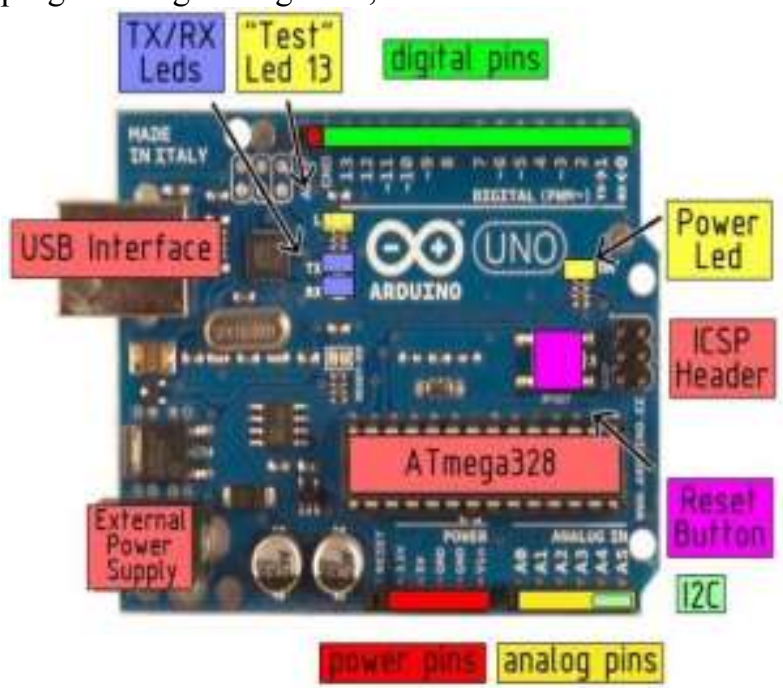

Figure 3: Arduino UNO

\subsubsection{GSM Modem}

It is a specialized kind of modem involving a SIM card holder, operating on a mobile operator subscription, in the same manner as that of a mobile phone device. A GSM model from the perspective of a mobile operator works in the same way as that of a mobile phone.

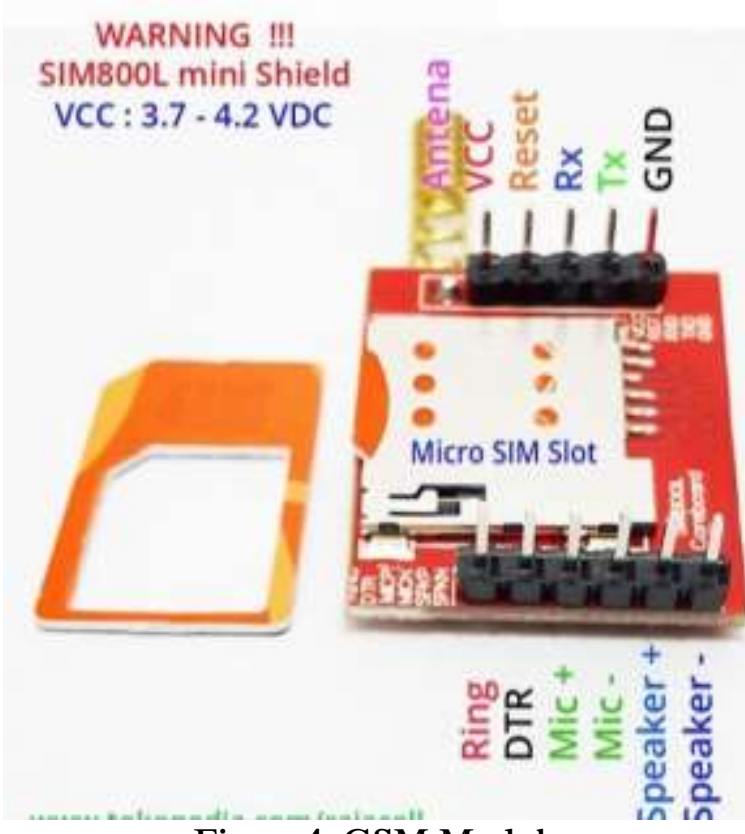

Figure 4: GSM Module

\subsubsection{Sensors}

Primarily only three types of sensors are connected in such devices:

(a) Humidity sensor: These types of sensors are getting more and more importance, in different fields of control and measurement technologies. Manufacturers are attempting to improve the long-term drift and accuracy of the sensors, which can help in increasing their durability to be applied in different devices and also simultaneously reduces the price and size of the component.

(b) Temperature Sensor: LM35 sensor series is an integrated circuit with output voltage linearly proportional to the centigrade temperature ( ${ }^{\circ}$ Celsius). These sensors have an advantage over the ${ }^{\circ}$ Kelvin calibrated temperature sensors, as the users are not required to subtract large values of constant voltages from the output for achieving Centigrade scaling.

(c) Soil Moisture Sensor: VH400 probes and sensors offering low-cost monitoring of the water and soil content. As a probe measured the dielectric soil constant using transmission line method, it is insensitive to water salinity, and is not prone to corrosion, same as the conductivity-probes. These probes are rugged, small in size and works on low power. This sensor is connected to the Nova5000, Multi-Log-PRO or Tri-Link data loggers. 

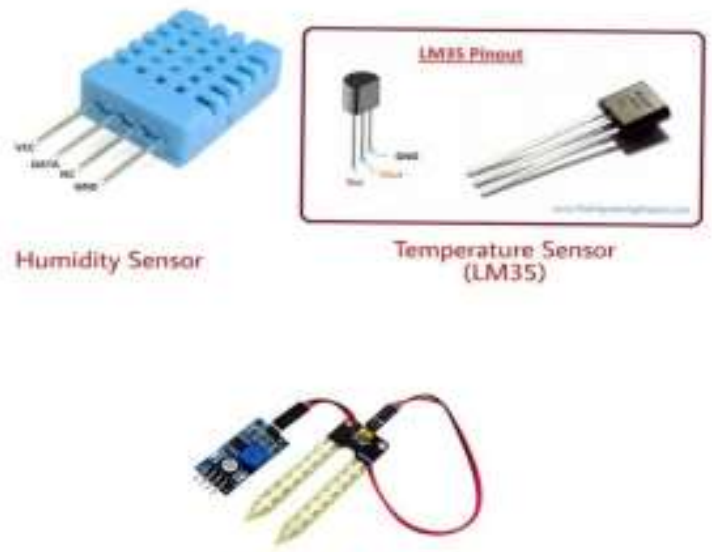

Soil Moisture Sensor

Figure 5: Sensors

\subsubsection{Relay}

A Relay power is controllable device, which is equipped with 4-outputs which helps in creating a IoT framework with reliable and safe power control. Using a power relay can help in easily controlling the power going to the system with Raspberry $\mathrm{Pi}$, Arduino, Microcontroller, and a single-board computer.

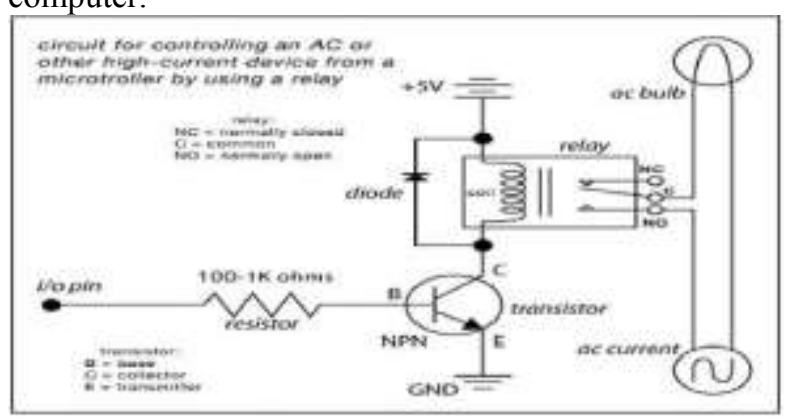

Figure 6: Relay Circuit Diagram

\subsubsection{Liquid Crystal Display}

An LCD, is a board used in different portable devices like computer, and in digital devices like watches. An LCD display uses two polarizing material sheets with a crystal liquid solution between the sheets. When current passes through this liquid, it causes the crystal to align together, so that the light cannot pass through these sheets. Therefore, every crystal act as a shutter, which either allows the light to block or pass through them. RCM2034R is a TN type reflective liquid crystal module with a built-in LSI driver/controller and display capacity of 1 line, 16 characters.

\subsubsection{Buzzer}

To mount on a PCB, a lout output buzzer is used, with following features:

Level of Sound Pressure(30cm): 85dB@5Vdc

Current Consumption:15mA@12Vdc

Operating Voltage: $1.5-27 \mathrm{Vdc}$

Rated Frequency: Continuous $4 \mathrm{KHz}$

\subsubsection{Power Supply}

In the project, a $9 \mathrm{~V}$ transformer is used to provide a continuous power supply. A continuous power supply is used, as in case if a battery is used the total current would be lost, hence an AC transformer is used. An AC transformer helps in providing an input to a Bridge Rectifier, this converter helps in converting AC to DC. After this 1 filter capacitor is used with $1000 \mathrm{uf} / 25 \mathrm{v}$ in a parallel geometry. The main aim of using a capacitor is to reduce any alternating occurring peaks. Nothing but a filtering that repulls. After the processing, a LM7805 Regulator is used in most of the digital logic circuits and processors required a $5 \mathrm{~V}$ power supply. Hence, for using these parts in the device, $5 \mathrm{~V}$ regulated source is required. First, a positive lead of the unregulated DC power supply is connected, after which the negative lead is connected to a common pin. The power is then turned $\mathrm{ON}$, and we get $5 \mathrm{~V}$ supply from the Output pin. In the figure below, red colour led is used to indicate the power.

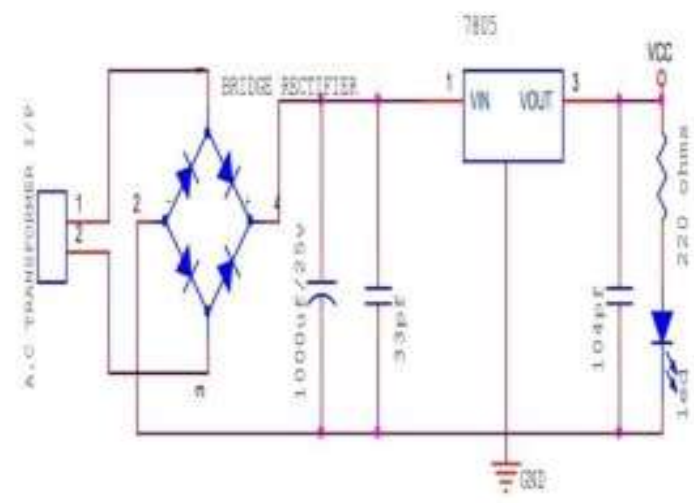

Figure 7: Power Supply Board Circuit Diagram

\section{RESULT}

The following Figure 8 shows the whole system which was successfully run and the reading has been taken by the different sensors and data is analysed if soil is not wet and temperature is high the water pump automatically starts and then when the water sufficient in the soil the water pump switches off and data is send to the farmer. 


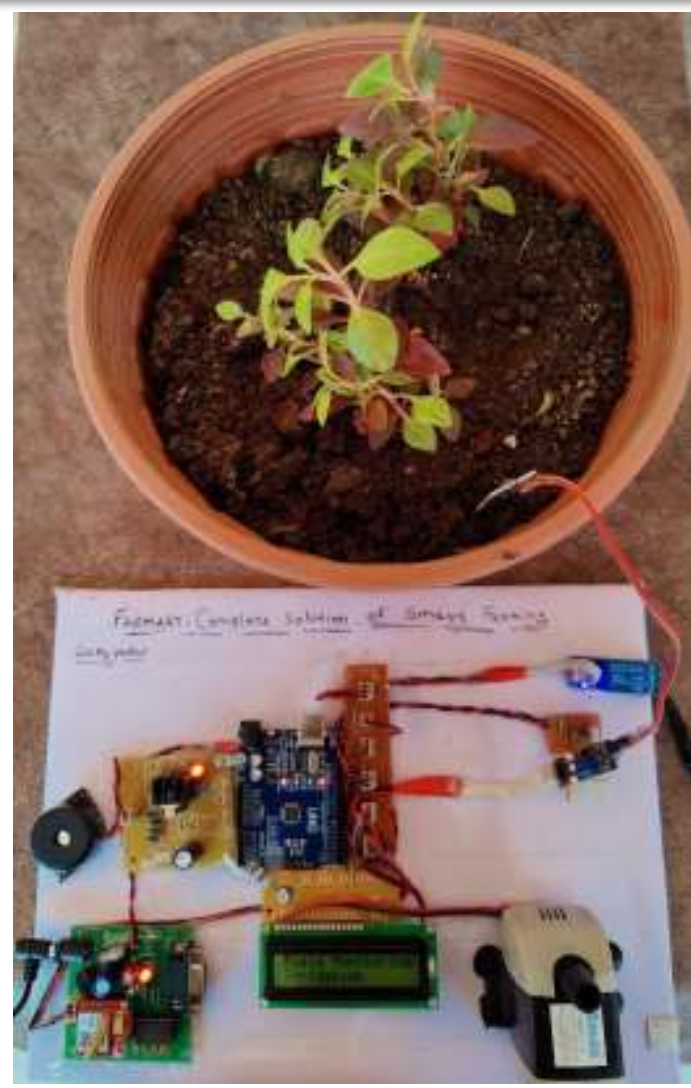

Figure 8: FARMART: IOT Based Smart Agriculture System

\section{Webpage images https://iotwaterquality.com/iot_farming/indexphp}

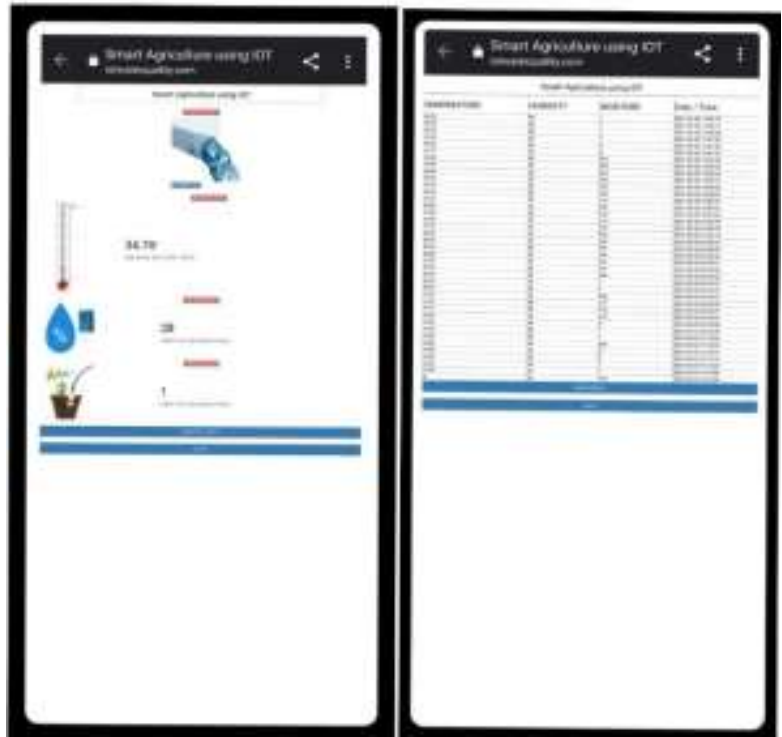

Figure 9: Webpage Screenshots

The following figure 9 shows the webpage images as the reading is taken the table is design to feed the data with date and time and in page 1 the live data is shown and in page 2 history of past data is shown. The farmer has to reach the given URL login their account and they will get the live data.
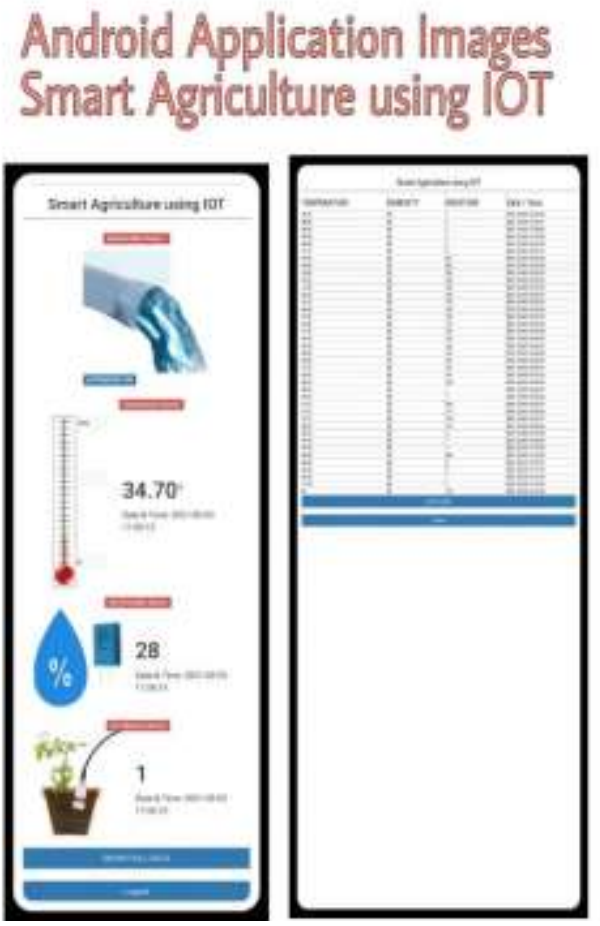

Figure 10: Android Application Screenshots

The following figure 10 shows the Android app images as the reading is taken the table is design to feed the data with date and time and in screen 1 the live data is shown and in screen 2 history of past data is shown. The farmer has to reach the given app which is Smart agriculture using IOT login their account and they will get the live data.

\section{CONCLUSION}

A smart Farming system is designed in this present research using the technology of Internet of Things, with Agriculture system, to monitor the soil moisture, temperature and the Humidity level using Android framework, with HTML and Arduino. The designed system shows higher accuracy and efficiency to fetch live data for the soil moisture level, temperature and humidity. The novel farming system presented in the paper, helps the farmer to increase their yield and helps them to take care of the produce, as the system also helps the farmers in getting accurate live feed for the outer temperature, soil moisture and humidity with $99 \%$ recorded efficient results and will also automatically irrigate the field.

\section{Future Scope}

In future the system can also include some more sensors for fetching more data, specially to control pest. An IOS application can also be design with new feature in android application and we will find more ways and make it easier to understand. 


\section{REFERENCES}

1. S. Sivachandran, K. Balakrishnan, K. Navin, "Real Time Embedded Based Soil Analyser", (IRJET) March 2014.

2. Chandan Kumar Sahu, Pramitee Behera, "A LowCost Smart Irrigation Control System" (ICECS2015)

3. IOT based smart sensors agriculture by Anand Nayyar and Er. Vikram Puri, November 2016.

4. Shakthipriya Netal."An Effective Method for Crop Monitoring Using Wireless Sensor Network"(2014

5. Nikhil Agrawal et al. "Smart Drip Irrigation System using Raspberry pi and Arduino" (2015)

6. Patil K. A. et al. "A Model for Smart Agriculture Using IOT" (2016)

7. G. Meena Kumari et al "Real -Time Automation and Monitoring System for Modernized Agriculture". (2014)

8. A RESEARCH PAPER ON SMART AGRICULTURE USING IOT Ritika Srivastaval, Vandana Sharma2, Vishal Jaiswal3, Sumit Raj4 (IRJET 2020)

9. Anand Nayyar, Er. Vikram Puri et al 2016, Smart Farming: IoT Based Smart Sensors Agriculture Stick for Live Temperature and Moisture Monitoring using Arduino, Cloud Computing \& Solar Technology

10. hi, X.; An, X.; Zhao, Q.; Liu, H.; Xia, L.; Sun, X.; Guo, Y., "State-of-the-Art Internet of Things in Protected Agriculture", Sensors 2019, 19, 1833.

11. O. Elijah, T. A. Rahman, I. Orikumhi, C. Y. Leow and M. N. Hindia, "An Overview of Internet of Things (IOT) and Data Analytics in Agriculture: Benefits and Challenges," in IEEE Internet of Things Journal, vol. 5, no. 5, pp. 3758-3773, Oct. 2018.

12. Thea K., Martin C., Jeffrey M., Gerhard E, Dimitrios Z, Edward M., Jeremy P., Food safety for food security: Relationship between global megatrends and developments in food safety", Trends in Food Science \& Technology, Vol 68,2017, Pages 160-175. 